\title{
Catheter Ablation of Paroxysmal Atrial Fibrillation Originating from Non-pulmonary Vein Areas
}

\author{
Satoshi Higa, ${ }^{1}$ Li-Wei LO ${ }^{2,3}$ and Shih-Ann Chen ${ }^{2,3}$ \\ 1. Cardiac Electrophysiology and Pacing Laboratory, Division of Cardiovascular Medicine, Makiminato Central Hospital, Okinawa, Japan; \\ 2. Heart Rhythm Center, Division of Cardiology, Department of Medicine, Taipei Veterans General Hospital, Taipei, Taiwan; \\ 3. Institute of Clinical Medicine, Department of Medicine, School of Medicine, National Yang-Ming University, Taipei, Taiwan
}

\begin{abstract}
Pulmonary veins (PVS) are a major source of ectopic beats that initiate AF. PV isolation from the left atrium is an effective therapy for the majority of paroxysmal AF. However, investigators have reported that ectopy originating from non-PV areas can also initiate AF. Patients with recurrent AF after persistent PV isolation highlight the need to identify non-PV ectopy. Furthermore, adding non-PV ablation after multiple AF ablation procedures leads to lower AF recurrence and a higher AF cure rate. These findings suggest that non-PV ectopy is important in both the initiation and recurrence of AF. This article summarises current knowledge about the electrophysiological characteristics of nonPV AF, suitable mapping and ablation strategies, and the safety and efficacy of catheter ablation of AF initiated by ectopic foci originating from non-PV areas.
\end{abstract}

\section{Keywords}

Atrial fibrillation, non-pulmonary vein, trigger, catheter ablation

Disclosure: The authors have no conflicts of interest to declare.

Received: 26 August 2018 Accepted: 16 November 2018 Citation: Arrhythmia \& Electrophysiology Review 2018;7(4):273-81. DoI: https://doi.org/10.15420/aer.2018.50.3 Correspondence: Shih-Ann Chen, Division of Cardiology, Department of Medicine, Taipei Veterans General Hospital, 201 Sec 2, Shih-Pai Road, Taipei, Taiwan.

E: epsachen@ms41.hinet.net

Catheter ablation of AF has become an established therapy and may have the potential to cure this most commonly encountered sustained arrhythmia. Previous studies have demonstrated that pulmonary veins (PVS) are a major source of the ectopic beats that initiate AF. PV isolation in patients with symptomatic paroxysmal AF refractory to antiarrhythmic drugs is effective; however, it is difficult to eliminate all instances of $A^{1-3}{ }^{1-3}$ If ectopic foci consistently come from a non-PV area and a pattern of spontaneous onset of AF is onset confirmed, the earliest ectopic site is defined as the non-PV trigger initiating $A F^{2,4-7}$ Ectopy originating from non-PV areas can initiate $A F$ and can cause it to recur after PV isolation. ${ }^{4-31}$ NonPV ablation after multiple AF ablation procedures decreases the risk of recurrence and increases the cure rate. 10,19-21,23,25,28,29 Although several ablation strategies have been developed, the outcomes of ablation are not improved unless substrate modification targets AF triggers. ${ }^{30}$ Taking all of these considerations into account, non-PV ectopy plays important role in both $\mathrm{AF}$ initiation and recurrence. . $^{2,-7,20,29,30,32-34}$

Mapping studies of non-PV foci have revealed that triggers are often found in anatomically predictable regions, such as the left atrial wall, thoracic veins and crista terminalis, and can be sustained or non-sustained triggers of AF. These areas can be mapped by specific multielectrode catheters positioned in key regions and ablated after the AF is induced and localised, or they can be ablated empirically without the induction of ectopy. ${ }^{1-34}$ This review focuses on catheter ablation of AF initiated by non-PV triggers, summarising the electrophysiological characteristics, mapping and ablation strategies, their safety and efficacy.

\section{Electrophysiological Features of AF Originating from Non-pulmonary Vein Areas}

Incidence of Initiators

Several important concepts have been proposed regarding the role of non-PV ectopy in initiating $A F^{2,4-7} A F$ is initiated by non-PV disturbance of the cardiac rhythm in up to $39 \%$ of cases. $3,8-10,32-38$ The left atrium (LA) $(25.3 \%)$, superior vena cava (SVC) $(22.2 \%)$, coronary sinus (CS) (18.0\%), right atrium (RA) including the crista terminalis (17.4\%), interatrial septum (7.9\%), and ligament of Marshall (LOM) (3.9\%) are the areas in which non-PV triggers of de novo AF are most commonly found (Table 1), whereas the SVC, interatrial septum and LA are the most common non-PV trigger sites in recurrent AF (Table 2). ${ }^{6-30}$ Furthermore, there is a higher incidence of non-PV triggers initiating $\mathrm{AF}$ in females and in patients with an enlarged LA. ${ }^{39}$

\section{Pathophysiology}

Histological analysis of the embryonic sinus venosus has identified areas capable of spontaneous depolarisation at the junctions between different embryonic tissues, such as the RA-SVC junction, crista terminalis and CS ostium. ${ }^{40-42}$ The SVC is a major origin of nonPV triggers of $A F^{5,8,82-34,43-47}$ Heterogeneity of the SVC sleeve and arrhythmogenicity of cardiomyocytes isolated from the SVC have been reported. ${ }^{41,42}$ An excitation from the SVC can conduct to the RA through the myocardial extensions of the SVC sleeve. ${ }^{48-50}$ Diseased human atria are hypopolarised in comparison to normal atria, which may account for the abnormal automaticity and/or activity originating from the LA wall. ${ }^{51-53}$ The crista terminalis, which is an area exhibiting abnormal automaticity, anisotropy and slow conduction, may serve 


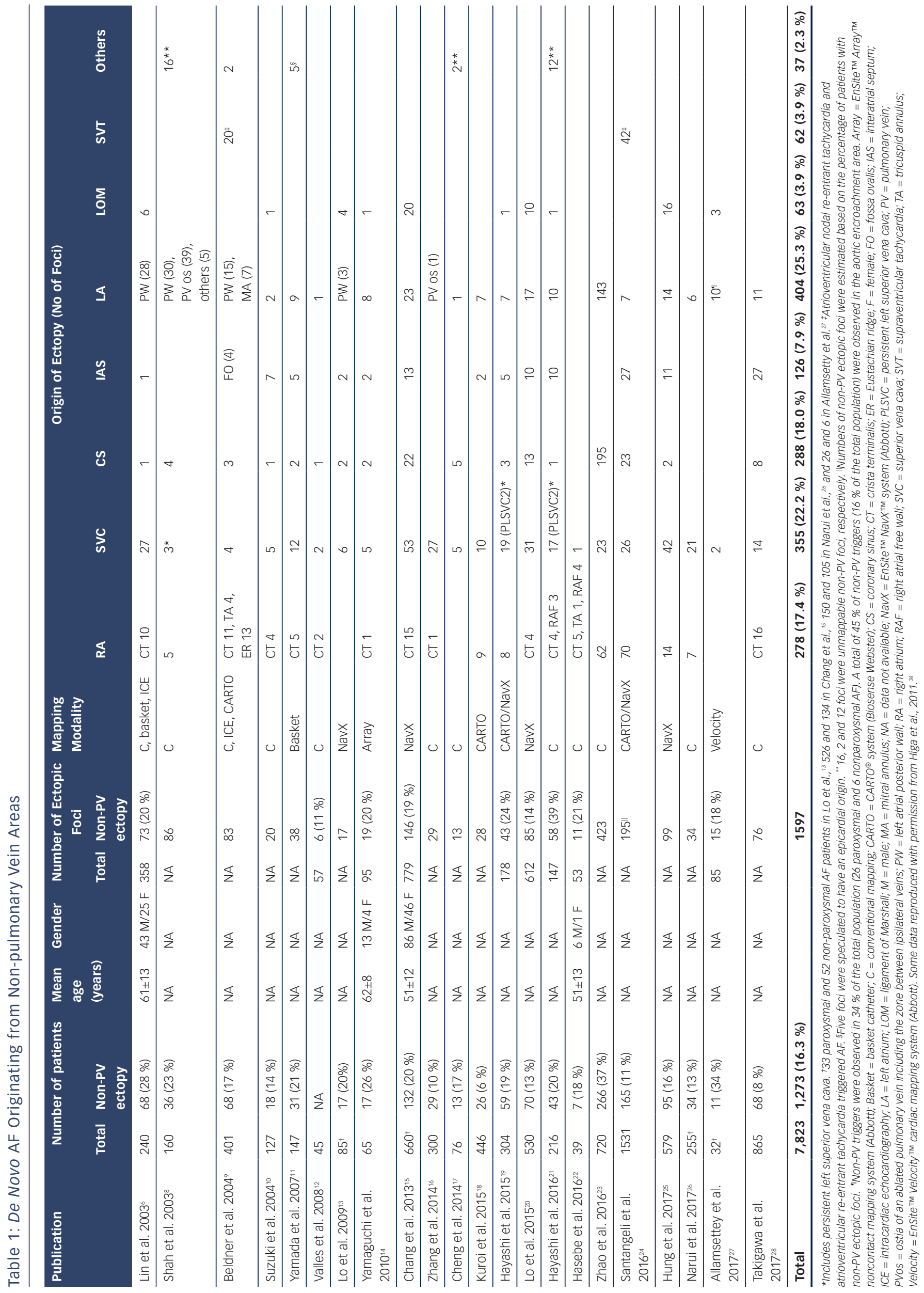




\begin{tabular}{|c|c|c|c|c|c|c|c|c|c|c|c|c|c|c|}
\hline \multirow[t]{2}{*}{ Publication } & \multicolumn{2}{|c|}{ Number of patients } & \multirow{2}{*}{$\begin{array}{l}\text { Mean } \\
\text { age } \\
\text { (years) }\end{array}$} & \multirow[t]{2}{*}{ Gender } & \multicolumn{2}{|c|}{ Number of Ectopic Foci } & \multirow{2}{*}{$\begin{array}{l}\text { Mapping } \\
\text { Modality }\end{array}$} & \multicolumn{7}{|c|}{ Origin of Ectopy (Percentage of Foci) } \\
\hline & Total & Non-PV ectopy & & & Total & Non-PV ectopy & & RA & SVC & CS & IAS & LA & LOM SVT & Others \\
\hline $\begin{array}{l}\text { Takigawa et al. } \\
2005^{29}\end{array}$ & 207 & $95(46 \%)^{*}$ & $63 \pm 11$ & $\begin{array}{l}69 \text { male/ } \\
26 \text { female }\end{array}$ & NA & 92 & C & & 34 & & 16 & 12 & & $38^{+}$ \\
\hline Lo et al. $2015^{20}$ & 94 & $11(12 \%)^{*}$ & NA & NA & 102 & $12(12 \%)$ & NavX & 8 & 25 & & 8 & 42 & 17 & \\
\hline Lo et al. $2015^{20}$ & 52 & $15(29 \%)^{\ddagger}$ & NA & NA & 75 & $24(32 \%)$ & NavX & 17 & 25 & 4 & & 42 & 13 & \\
\hline $\begin{array}{l}\text { Mahonty et al. } \\
2017^{30}\end{array}$ & 84 & $74(88 \%)^{\S}$ & NA & NA & NA & NA & CARTO & & $9 \|$ & 64 & 22 & 69 & & \\
\hline
\end{tabular}

*Incidence of non-PV foci during a second session of catheter ablation of paroxysmal AF. ${ }^{+}$In this study,35 foci (38 \%) were unmappable non-PV foci. ${ }^{\prime}$ Incidence of non-PV foci during the third to fifth catheter ablation of paroxysmal AF. IIncidence of non-PV foci during a second session of catheter ablation of paroxysmal AF with severe left atrial scarring. The non-PV triggers were mostly (90.5\%) located in areas outside the scar region. $19 \%$ of non-PV foci were located on the crista terminalis/superior vena cava. $C=$ conventional mapping; CARTO $=$ CARTO ${ }^{\otimes}$ System (Biosense Webster); $C S=$ coronary sinus; IAS = interatrial septum; $L A=$ left atrium; $L O M=$ ligament of Marshall; $N A=$ data not available; NavX = EnSite ${ }^{\mathrm{TM}}$ NavX ${ }^{\mathrm{TM}}$ system (Abbott); $R A=$ right atrium; SVC = superior vena cava; SVT = supraventricular tachycardia. Some data reproduced with permission from Higa et al., 2011. ${ }^{34}$

as an arrhythmogenic substrate for AF initiation and perpetuation. ${ }^{54,55}$ Catecholamine-sensitive ectopy arising from the crista terminalis exhibits high-frequency depolarisations with fibrillatory conduction. ${ }^{6}$ The LOM is an embryological remnant of the left SVC and contains arrhythmogenic myocardial fibres with sympathetic innervation. Several reports have demonstrated the existence of catecholaminesensitive tissue within the LOM that has abnormal automaticity, and which could be a potential source of AF initiation.., $56-58$

The musculature within the CS also has arrhythmogenic activity, with spontaneous depolarisations induced by catecholamine loading. ${ }^{59,60}$ Abnormal dilatation due to an unroofed CS can be an arrhythmogenic focus of AF initiation. ${ }^{61}$ A recent study found that $45 \%$ of non-PV triggers of AF were in the area of aortic encroachment, which equates to $16 \%$ of the total population with AF. There is also an arrhythmogenic substrate exhibiting low voltage and fractionated electrograms with a prolonged duration in the anterior part of the LA at the site of aortic encroachment. ${ }^{27}$

\section{Diagnosis}

\section{Provoking Ectopy}

To successfully provoke ectopy with AF initiation, antiarrhythmic drugs should be discontinued for a period of at least five half-lives before the patient undergoes electrophysiological study. Spontaneous initiation of ectopic beats preceding AF should be observed at baseline or after isoproterenol loading. ${ }^{32-34}$ In the case of deep sedation or general anaesthesia, it is necessary to give the patient a high dose of isoproterenol to induce ectopy with AF initiation. Adenosine or adenosine triphosphate can also be used, especially in young patients with vagal $A F$ and with a family history of AF. ${ }^{18}$

If ectopy does not occur, short-burst atrial pacing can be delivered with intermittent pauses or, failing that, atrial burst pacing to induce sustained AF. Careful monitoring for spontaneous reinitiation of AF is required after internal or external cardioversion. The induction of spontaneous AF initiation should be attempted at least twice to confirm the location of ectopy, the initiation pattern of spontaneous AF, and the earliest activation site (the AF initiator). 2,4-7,32-34

\section{Mapping}

Localisation of AF triggers is important for the catheter ablation of AF. If it is suspected that the trigger is based in the LA, a decapolar catheter should be inserted into the CS via the internal jugular vein and a circular mapping catheter placed in the LA using a transseptal approach. If the initiator is likely to be in the RA, a duodecapolar catheter can be placed from the crista terminalis to the distal SVC for the simultaneous mapping of the right PVs, crista terminalis and SVC. Endocardial activation timing from the high RA, His bundle and distal/proximal portion of the CS can be used to predict non-PV ectopy (Figure 1). ${ }^{2,4-7,32-34}$ It is $100 \%$ accurate in discriminating ectopy from the SVC or upper portion of the crista terminalis from PV ectopy. ${ }^{32-34,62}$ The interatrial septum should be the suspected initiator in cases with a monophasic positive narrow $\mathrm{P}$ wave in lead $\mathrm{V}_{1}$ or a relatively short activation time ( $\leq 15 \mathrm{~ms}$ ) preceding P wave onset during ectopy. Simultaneous mapping of the right- and left-sided interatrial septum should be performed to avoid any misdiagnosis. ${ }^{32-34,63,64}$

\section{AF Initiators with Right Atrial Origin}

Careful observation of $\mathrm{P}$ wave morphology is useful for predicting the approximate location of AF ectopy. ${ }^{32-34,65} \mathrm{~A}$ negative $\mathrm{P}$ wave or the presence of a negative component in $\mathrm{V}_{1}$ is predictive of an $\mathrm{RA}$ origin of $\mathrm{AF}$ initiation. Ectopy originating from the SVC or upper portion of the crista terminalis exhibits upright $P$ waves in the inferior leads; ectopy from the CS ostium produces negative P wave polarity in the inferior leads; and ectopy from the middle portion of the crista terminalis results in biphasic $P$ waves. Negative $P$ waves with a long duration in $V_{1}$ may be associated with RA free-wall ectopy, including the tricuspid annulus.

If RA AF ectopy is suspected, the use of a duo-decapolar catheter is useful for mapping along the crista terminalis to the SVC. ${ }^{2,4-7,32-34}$ Bipolar signals from the proximal portion of the SVC usually exhibit a blunted atrial signal followed by a discrete sharp SVC signal during sinus rhythm. ${ }^{32-34}$ The activation sequence of these double potentials is reversed during SVC ectopy. Bipolar signals from the distal part of the SVC usually exhibit double potentials: the first component represents a SVC near-field sharp potential; and the second component, a right superior PV far-field blunted signal. During SVC ectopy, the activation sequence of these double potentials remains unchanged. The activation sequence is reversed during right PV ectopy.

Intracardiac recordings along the crista terminalis also exhibit double potentials during sinus rhythm, with a high-to-low activation sequence. ${ }^{32-34}$ During crista terminalis ectopy, the atrial activation sequence of the double potentials is reversed. Noncontact mapping using an EnSite ${ }^{\mathrm{TM}}$ Array ${ }^{\mathrm{TM}}$ (Abbott) can accurately localise the ectopic foci with discrete depolarisations and clarify crista terminalis gap conduction-related small radius re-entry. ${ }^{32-34,66}$ 


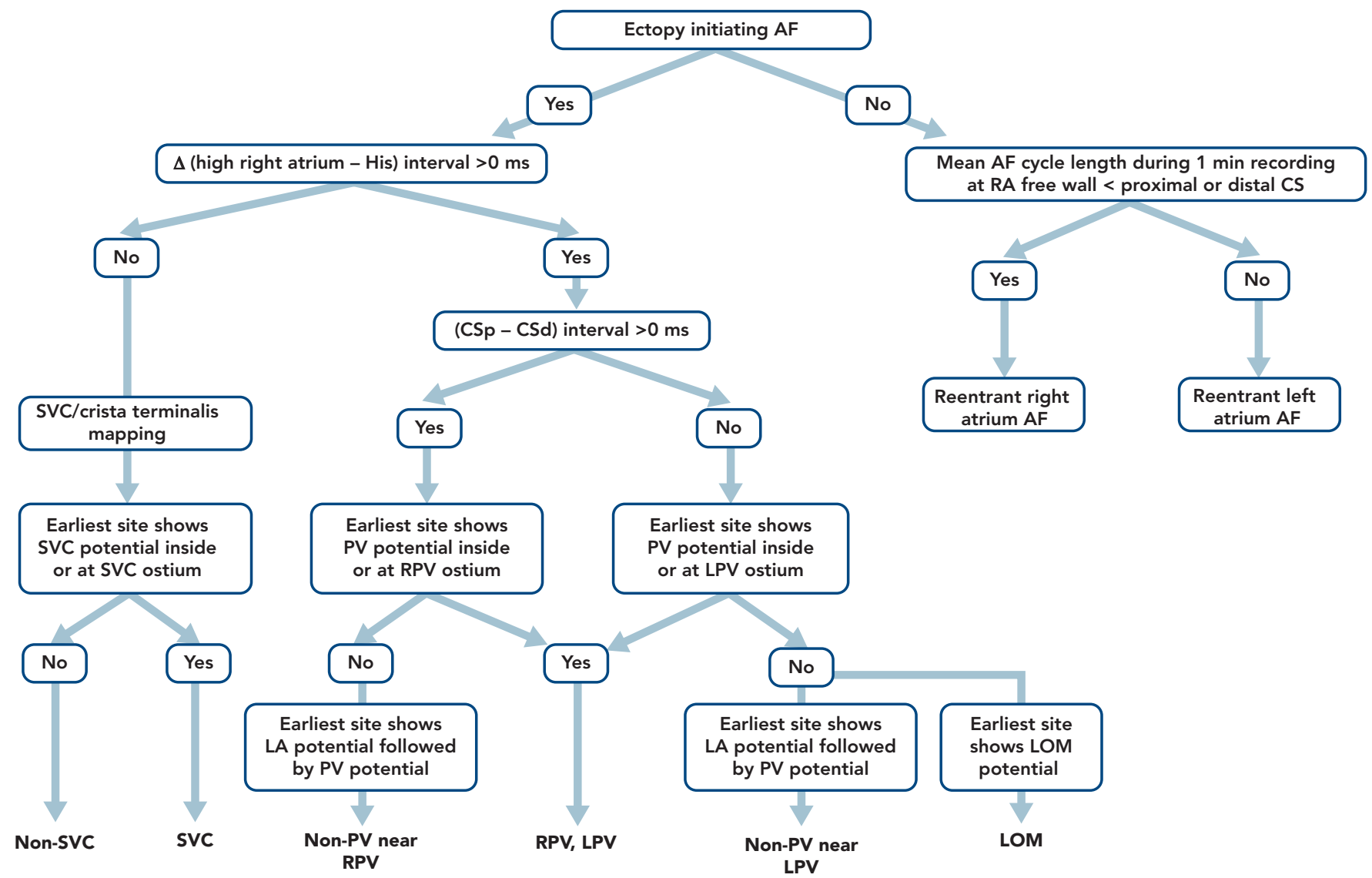

$\Delta$ (high right atrium - His) represents the time interval from the high right atrial electrogram onset to the onset of the His atrial electrogram during sinus beats minus the same interval measured during ectopic atrial activity. CSP - CSd represents the difference in the atrial activation time between the proximal (p) and distal (d) CS atrial electrograms during an ectopic atrial beat. Source: Higa et al., 2006. ${ }^{32}$ Reproduced with permission from Elsevier. CS = coronary sinus; LOM = ligament of Marshall; LPV = left pulmonary vein; PV = pulmonary vein; $R P V=$ right pulmonary vein; SVC = superior vena cava.

\section{AF Initiators with Left Atrial Origin}

The time interval between the atrial activation of the decapolar catheter in the proximal CS and that in the distal CS is useful for predicting ectopic foci located near the right ( $>0 \mathrm{~ms}$ ) or left PV antrum ( $<0 \mathrm{~ms}$ ) (Figure 1). ${ }^{32-34,62}$ During sinus rhythm, the fusion potentials of a blunt signal and a rapid, deflecting sharp signal can be observed in the areas between the LA posterior wall and the PV antrum. The fusion potential consists of atrial and PV signals and can be found at the earliest activation site during LA posterior or PV antral ectopy. An alternating pattern of atrial and PV potentials can also be seen during ectopy. ${ }^{6,32-34}$

The Marshall ligament has multiple electrical connections to the musculature of the CS, LA posterior free wall and left PV; therefore, it is essential to differentiate a Marshall potential from a left PV or LA posterior free wall potential. A differential pacing method and/or direct recording of the LOM potential by a microelectrode catheter cannulated into the vein of Marshall can distinguish a PV potential from a Marshall potential (Tables 3 and 4). ${ }^{7,32-34,56,67,68}$

According to expert consensus statements, complex fractionated atrial electrogram (CFAE)-targeted ablation after PV isolation is feasible for substrate modification. ${ }^{69}$ Interestingly, our laboratory reported a close anatomical relationship between the distribution of CFAEs and non-PV AF initiators. All of the nonPV AF initiators were associated with continuous CFAE sites. ${ }^{70,71}$
Recently, the efficacy of a novel self-reference mapping technique using a PentaRay ${ }^{\circledR}$ catheter (Biosense Webster) to localise non-PV triggers originating from the LA has been reported. ${ }^{72}$

\section{Limitations of Mapping}

AF ablation can be a challenging and sometimes cumbersome task in cases of unmappable infrequent beats originating from uncommon areas. Activation mapping using fixed multipolar catheters and point-by-point mapping are not efficient for the identification of target ectopies in such cases. Single-beat analysis by noncontact mapping using the Array ${ }^{\top M}$ system (Figure 2) or non-invasive bodysurface mapping using the Cardiolnsight ${ }^{\top M}$ Mapping vest system (Medtronic) can be useful tools in these situations. ${ }^{73}$

\section{Ablation}

The earliest bipolar electrogram site with unipolar QS pattern recorded from the origin is the ablation target for non-PV ectopy.,24-7,32-34 Ablation of an ectopic focus and/or electrical isolation of an arrhythmogenic thoracic vein can be achieved with the application radiofrequency energy for around 30 seconds with a non-irrigated tip at $50-55{ }^{\circ} \mathrm{C}$ or with an irrigated tip at $<25-30 \mathrm{~W}^{2,4-6,32-34}$ A contact force catheter can be used to create durable transmural lesions. This method has a lower arrhythmia recurrence and a lower incidence of atrial tachyarrhythmias resulting from incomplete ablation due to proarrhythmic lesion gaps. However, caution should be taken to avoid the application of excessive 
energy and/or contact pressure at the posterior LA wall close to the oesophagus.

Balloon-based cryoablation of the PV antral area, LA posterior wall and persistent left SVC can also be used to isolate arrhythmogenic myocardium. Complications can be minimised by using a cryocatheter at $-30{ }^{\circ} \mathrm{C}$ to ice map the area near the atrioventricular node following the cryofreezing $\left(-80^{\circ} \mathrm{C}\right)$ of a para-Hisian or $\mathrm{CS}$ ostium trigger. Ice mapping can also be used during ablation near the sinus node when targeting SVC or the upper portion of the crista terminalis. Repeated AF induction protocols should be performed after ablation to assess the non-inducibility of the ablated ectopy. ${ }^{24-7,32-34}$

\section{Vena Cava Triggers}

Electrical disconnection between the arrhythmogenic SVC and RA at the level of the RA-SVC junction is the preferred approach for minimising AF recurrence and SVC stenosis in patients with SVC triggers. ${ }^{32-34}$ The aim is to establish bidirectional (entrance and exit) conduction block between the RA and SVC. ${ }^{5,32-34,47}$ Circular and basket catheters, and 3D mapping systems including the CARTO ${ }^{\circledR}$ (Biosense Webster), EnSite ${ }^{T M}$ NavX'TM Velocity (Abbott), EnSite ${ }^{T M}$ Array $^{\mathrm{TM}}$ noncontact mapping system, and Rhythmia HDx ${ }^{\mathrm{TM}}$ mapping system with IntellaMap Orion ${ }^{\mathrm{TM}}$ catheter (Boston Scientific) can guide SVC isolation. $6,32-34,44-46,74-77$

Persistent left SVC is also a well-recognised trigger site for AF. 19,21,78-85 The connecting musculature means that multiple electrical signals are conducted to the posterolateral LA and middle portion of the CS from the left SVC trigger site. Complete left SVC isolation may be challenging, as it is close to the oesophagus and left phrenic nerve. There have been rare reports of inferior vena cava triggers. ${ }^{86,87}$ In these cases, the IVC triggers were successfully eliminated with a focal/isolation strategy.

\section{Interatrial Septal Triggers}

Focal ablation of the earliest activation site preceding the onset of AF should be performed until a complete elimination of the ectopy is achieved in patients with interatrial septal triggers. Near-simultaneous atrial activation of the multielectrode catheters located in the high RA, His bundle region and CS ostium can be observed in such cases. Simultaneous mapping of the right and left atrial septum is crucial to successfully locate and ablate this trigger.

\section{Crista Terminalis Triggers}

Focal ablation of the earliest activation site in the crista terminalis during ectopy preceding AF onset should be performed until complete elimination of the ectopy initiating $A F$ or $>50 \%$ reduction in the amplitude of the initial local electrogram at the ablation site. ${ }^{6,32-34} \mathrm{~A}$ region with transverse gap conduction in the crista terminalis can be an arrhythmogenic source of re-entry and also ectopy initiating AF. Linear ablation of the transverse gap should address both of these problems. ${ }^{32-34,66}$ Intracardiac echocardiography can provide real-time monitoring of the anatomical relationship between the crista terminalis and the catheter position during the procedure.

\section{Coronary Sinus Triggers}

For patients with a CS trigger, electrical isolation of the arrhythmogenic CS musculature from the atrium by endocardial and/or epicardial ablation under the guidance of a 3D mapping system is preferable. ${ }^{32-34,71}$ The aim is to eliminate (entrance block) and/or dissociate (exit block) the CS potential. ${ }^{88-91}$ Care must be taken if an inappropriate
Figure 2: Mapping of Non-pulmonary Vein Triggers

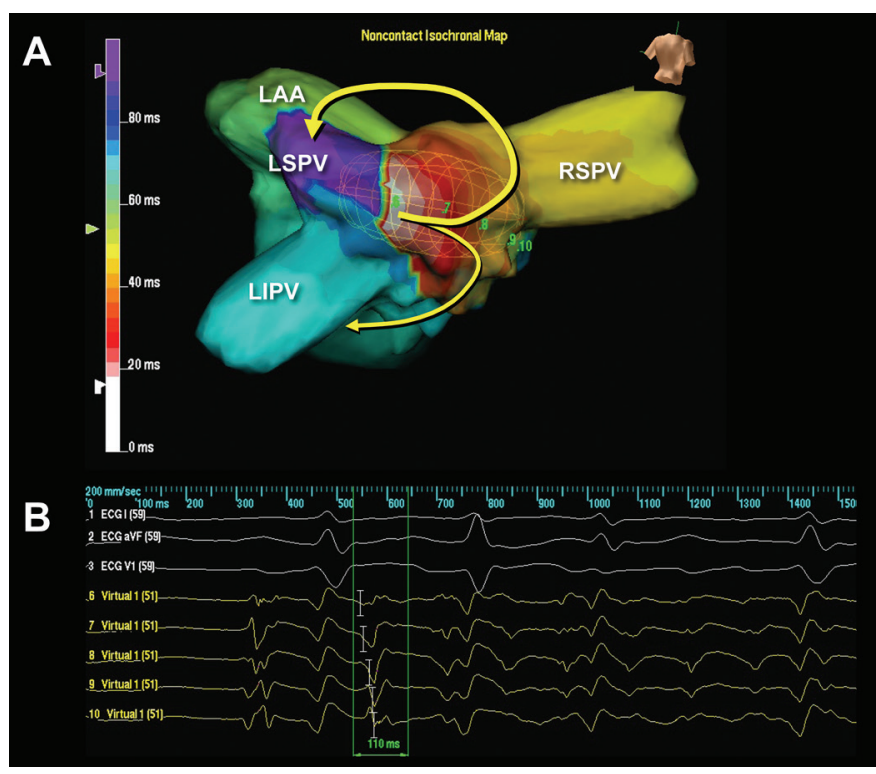

(A) An isochronal map during an ectopy-initiated AF. During the ectopy, a focal activation originates from the left atrial middle posterior wall with unidirectional conduction block on the left side of the posterior wall, and the activation wavefront preferentially conducts toward the right pulmonary veins and spreads out to the rest of the left atrium (yellow arrows) followed by AF. (B) The unipolar virtual signals demonstrate "QS" morphology at the origin (virtual 6, from the second beat) and " $r$ " morphology (virtual 8, from the second beat) at the breakout site. Source: Higa et al., 2008. ${ }^{73}$ Reproduced with permission from Dr Jonathan S Steinberg. $L A A=$ left atrial appendage; $L I P V=$ left inferior pulmonary vein; $L S P V=$ left superior pulmonary vein; $R S P V=$ right superior pulmonary vein.

impedance rise occurs during CS ablation, and the application of radiofrequency energy should be stopped immediately to prevent any steam pops.

\section{Marshall Ligament Triggers}

For patients with Marshall ligament triggers, the earliest site with a LOM potential preceding the onset of AF is targeted using an endocardial and/or epicardial approach.32-34,92 The isolation of both the LOM and left PVs from the LA can be monitored with simultaneous mapping of the LOM and left PV ostia, maximising the chance of a successful procedure. ${ }^{32-34,56,67,93}$ Ethanol infusion into an arrhythmogenic vein of Marshall through angioplasty guidewire and balloon catheter in addition to PV isolation has recently been reported to have beneficial outcomes. ${ }^{94,95}$

\section{Left Atrial Triggers}

For ectopy from the LA posterior wall, focal ablation of the earliest activation site should be performed (Figure 2). If unsuccessful, a boxshaped linear ablation needs to be added around the ectopy. ${ }^{6,32-34}$ Box isolation of the LA posterior wall in combination with PV isolation may be a therapeutic option in cases refractory to extensive focal ablation. The endpoint is complete elimination of the ectopy initiating $A F,>50 \%$ reduction in the electrogram amplitude of the ectopic focus, or isolation of the posterior LA wall. ${ }^{32-34,73}$

The left atrial appendage (LAA) has been reported to be a trigger of AF. ${ }^{96}$ Due to its large structure, triggers may arise from the LAA ostium, body or tip. Simultaneous mapping of the left superior PV and LAA can differentiate between a near-field sharp and a far-field blunt signals and identify true LAA triggers. Focal ablation can be applied to avoid LAA isolation. LAA isolation is only indicated when the patient can tolerate long-standing anticoagulation or a LAA occlusion device is indicated. 
Table 3: Diagnostic Criteria for Non-pulmonary Vein Ectopy Initiating AF

\begin{tabular}{|c|c|}
\hline Location & Criteria \\
\hline $\begin{array}{l}\text { AF initiators from the right } \\
\text { atrium }\end{array}$ & $\begin{array}{l}\text { - Difference in the time interval between the atrial activation at the high right atrium and His bundle area during sinus rhythm } \\
\text { and ectopy of }<0 \mathrm{msec}\end{array}$ \\
\hline $\begin{array}{l}\text { Inferior vena cava, superior } \\
\text { vena cava }\end{array}$ & $\begin{array}{l}\text { - Positive (superior vena cava) and negative (inferior vena cava) P waves in the inferior leads and positive or biphasic } \mathrm{P} \text { waves } \\
\text { in } \mathrm{V}_{1} \text { (superior vena cava) } \\
\text { - Earliest ectopic activity in the vena cava during simultaneous mapping of the vena cava and right pulmonary vein (PV) } \\
\text { - Reversal of the double-potential sequence during ectopy (vena cava potentials with a rapid deflection-far-field atrial potential } \\
\text { sequence; distal-to-proximal venous activation sequence) }\end{array}$ \\
\hline Crista terminalis (CT) & $\begin{array}{l}\text { - Polarity of the P waves in the inferior leads: upper portion of the CT, positive; middle portion, biphasic; lower portion, negative } \\
\text { - Earliest ectopic activity along the CT during simultaneous mapping of the CT, vena cava and right PV }\end{array}$ \\
\hline Coronary sinus ostium & $\begin{array}{l}\text { - Negative P waves in the inferior leads } \\
\text { - Earliest ectopic activity in the coronary sinus ostium }\end{array}$ \\
\hline AF initiators from left atrium & $\begin{array}{l}\text { - Difference in time interval between the atrial activation at the high right atrium and His bundle area during sinus rhythm and } \\
\text { ectopy of }>0 \mathrm{msec}\end{array}$ \\
\hline $\begin{array}{l}\text { Left atrial free wall or } \\
\text { left atrial appendage }\end{array}$ & - Atrial potentials with a rapid deflection-PV potential found after the earliest atrial activation \\
\hline $\begin{array}{l}\text { Ligament of Marshall } \\
\text { (LOM) }\end{array}$ & $\begin{array}{l}\text { - Earliest activation site along the vein of Marshall, posterolateral portion of the mitral annulus or left PV ostium } \\
\text { - Reversal of the triple-potential sequence; the LOM potential is earlier than the left atrium or left PV potentials (LOM-left } \\
\text { atrium-PV potentials sequence) }\end{array}$ \\
\hline
\end{tabular}

CT = crista terminalis; LOM = ligament of Marshall; $P V=$ pulmonary vein. Source: Higa et al., 2006. ${ }^{33}$ Reproduced with permission from Elsevier.

Table 4: Targets for Ablation of AF Originating from Non-pulmonary Vein Areas

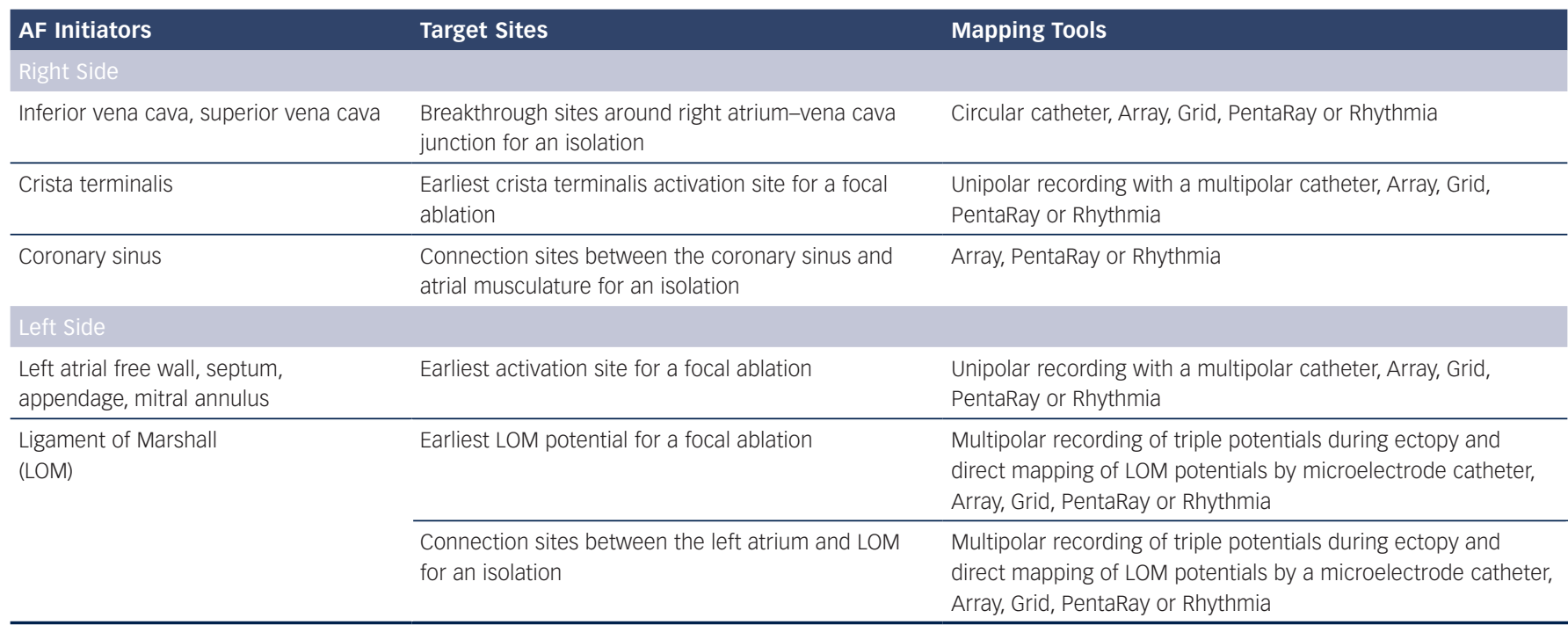

Array = EnSite ${ }^{\mathrm{TM}}$ Array ${ }^{\mathrm{T} \mathrm{M}}$ Noncontact Mapping System (Abbott); Grid = Advisor ${ }^{\mathrm{TM}}$ HD Grid Mapping Catheter (Abbott); LOM = ligament of Marshall; PentaRay = PentaRay ${ }^{\circledR}$ Catheter (Biosense

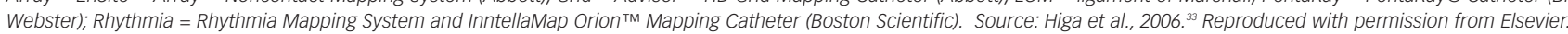

\section{Efficacy and Safety of Catheter Ablation}

Ablation Outcomes

A relatively high success rate has been demonstrated following the ablation of RA triggers of $\mathrm{AF}^{6}{ }^{6}$ There is a comparatively higher recurrence rate following the ablation of LA triggers. The average success, recurrence and complication rates are $99.3 \%$, $18.5 \%$, and $1.9 \%$, respectively, for AF originating from the vena cava. ${ }^{8,4-45,74,78-87,97-111}$ These rates are $78.0 \%, 16.7 \%$, and $2.4 \%$, respectively, for AF originating from the Marshall ligament. $6.56,67,68,94,112,113$

A higher incidence of recurrent $A F$ and non-PV AF sources has been reported in patients with metabolic syndrome and obstructive sleep apnoea. ${ }^{114}$ Patients who have a greater extent of left atrial delayed enhancement on MRI have a higher recurrence rate after $\mathrm{PV}$ isolation, suggesting the existence of AF triggers in non-PV areas. ${ }^{115}$

\section{Managing Complications}

Overall complication rates are now relatively low as a result of vast improvements in our understanding of the nature and ablation of non-PV ectopy AF triggers. Injury to the sinus node, atrioventricular node, and phrenic nerve, thoracic vein stenosis, peri-oesophageal damage, gastric hypomotility, and pyloric spasms can all be caused by a non-PV trigger ablation. ${ }^{116-124}$

Complications can be minimised by using a titrated and minimum power setting, short duration of radiofrequency energy, and by monitoring for any sinus rate accelerations, PR or RR interval prolongations and for oesophageal temperature rises. An upstream pacing technique to monitor the phrenic nerve and/or compound muscle action potential can minimise phrenic nerve injury. To reduce the risk of atrio-oesophageal fistula formation, which carries a 60-75\% chance of mortality, 
surgeonsshould avoid extensive high-power ablation on the LA posterior and CS walls. 119,121,122,125

The use of several luminal oesophageal temperature monitoring systems - SensiTherm ${ }^{\mathrm{TM}}$ (Abbott) and CIRCA S-Cath'M (CIRCA Scientific) - and protection systems, including oesophageal warming/cooling devices and deviators to avoid thermal injury, has recently been reported. ${ }^{126-130}$ Massive air emboli and newly developed thrombi that occur during the ablation procedure can be aspirated. ${ }^{131}$

\section{Conclusion}

Evidence suggests that inducing the non-PV ectopic trigger responsible for initiating AF both before and after PV isolation is an indispensable step in both initial and repeat ablation/isolation procedures. Advances in mapping and alternative energy modalities with 3D navigation are likely to play an important role in the ablation of non-PV ectopy. Together, these advances and the systematic identification of the trigger foci and their successful elimination will improve overall AF ablation outcomes.

\section{Clinical Perspective}

- The mechanisms of paroxysmal AF originating from nonpulmonary vein areas are automaticity, triggered activity, and microreentry.

- The diagnosis is made on the basis of a spontaneous onset of the ectopic beats initiating AF during baseline or after provocative manoeuvres.

- The earliest activation sites are the targets for focal ablation.

- The myocardial sleeve surrounding the ostium of the vena cava is the target for isolation.

- Success rates are $>99 \%$ for the vena cava and $78 \%$ for the ligament of Marshall.
1. Haissaguerre $\mathrm{M}$, Jais $\mathrm{P}$, Shah $\mathrm{DC}$, et al. Spontaneous initiation of atrial fibrillation by ectopic beats originating in the pulmonary veins. N Engl J Med 1998;339:659-66. https://doi. org/10.1056/NEJM199809033391003; PMID: 9725923.

2. Chen $\mathrm{SA}$, Hsieh $\mathrm{MH}$, Tai $\mathrm{CT}$, et al. Initiation of atrial fibrillation by ectopic beats originating from the pulmonary veins: Electrophysiological characteristics, pharmacological responses, and effects of radiofrequency ablation. Circulation 1999;100:1879-86. https://doi.org/10.1161/01.CIR.100.18.1879; PMID: 10545432

3. Oral $\mathrm{H}$, Knight BP, Tada $\mathrm{H}$, et al. Pulmonary vein isolation for paroxysmal and persistent atrial fibrillation. Circulatio 2002;105:1077-81. https://doi.org/10.1161/hc0902.104712; PMID: 11877358

4. Chen SA, Tai CT, Yu WC, et al. Right atrial focal atrial fibrillation: Electrophysiologic characteristics and radiofrequency catheter ablation. J Cardiovasc Electrophysiol 1999:10:328-35. https://doi.org/10.1111/.1540-8167.1999. 1999; 10:328-35. https://doi.
tb00679.x; PMID: 10210494 .

5. Tsai CF, Tai CT, Hsieh MH, et al. Initiation of atrial fibrillation by ectopic beats originating from the superior vena cava: Electrophysiological characteristics and results of radiofrequency ablation. Circulation 2000;102:67-74. https://doi.org/10.1161/01.CIR.102.1.67; PMID: 10880417.

6. Lin WS, Tai CT, Hsieh MH, et al. Catheter ablation of paroxysmal atrial fibrillation initiated by non-pulmonary vein ectopy. Circulation 2003;107:3176-83. https://doi. org/10.1161/01.CIR.0000074206.52056.2D; PMID: 12821558.

Tai CT, Hsieh MH, Tsai CF, et al. Differentiating the ligament of Marshall from the pulmonary vein musculature potentials in patients with paroxysmal atrial fibrillation: Electrophysiological characteristics and results of radiofrequency ablation. Pacing Clin Electrophysiol 2000;23:1493501. https://doi.org/10.1046/j.1460-9592.2000.01493.x; PMID: 11060869.

8. Shah DC, Haissaguerre M, Jais $\mathrm{P}$, et al. Nonpulmonary vein foci: Do they exist? Pacing Clin Electrophysiol 2003;26:1631-5. https://doi.org/10.1046/j.1460-9592.2003.t01-1-00243.x; PMID: 12914614

9. Beldner SJ, Zado ES, Lin D, et al. Anatomic targets for nonpulmonary triggers: Identification with intracardiac echo and magnetic mapping. Heart Rhythm 2004;1(suppl):S237. https://doi.org/10.1016/j.hrthm.2004.03.052.

10. Suzuki K, Nagata Y, Goya M, et al. Impact of non-pulmonary vein focus on early recurrence of atrial fibrillation after pulmonary vein isolation. Heart Rhythm 2004;1(Suppl):S203-4. https://doi.org/10.1016/j.hrthm.2004.03.051

11. Yamada T, Murakami Y, Okada T, et al. Non-pulmonary vein epicardial foci of atrial fibrillation identified in the left atrium after pulmonary vein isolation. Pacing Clin left atrium after pulmonary vein isolation. Pacing Clin
Electrophysiol 2007;30:1323-30. https://doi.org/10.1111/j.15408159.2007.00865.x; PMID: 17976093

12. Valles $E$, Fan $R$, Roux JF, et al. Localization of atrial fibrillation triggers in patients undergoing pulmonary vein isolation: importance of the carina region. J Am Coll Cardiol 2008;52 1413-20. https://doi.org/10.1016/j.jacc.2008.07.025; PMID: 18940533

13. Lo LW, Tai CT, Lin YJ, et al. Predicting factors for atrial fibrillation acute termination during catheter ablation procedures: implications for catheter ablation strategy and long-term outcome. Heart Rhythm 2009;6:311-8. https://doi. long-term outcome. Heart Rhythm 2009;6:311-8. https:/
org/10.1016/j.hrthm.2008.11.013; PMID: 19251203.

14. Yamaguchi T, Tsuchiya T, Miyamoto K, et al. Characterization of non-pulmonary vein foci with an EnSite array in patients with paroxysmal atrial fibrillation. Europace 2010;12:1698-706. https://doi.org/10.1093/europace/euq326; PMID: 21097479.

15. Chang HY, Lo LW, Lin YJ, et al. Long-term outcome of catheter ablation in patients with atrial fibrillation originating from nonpulmonary vein ectopy. J Cardiovasc Electrophysio 2013;24:250-8. https://doi.org/10.1111/jce.12036; PMID: 23210627

16. Zhang J, Tang C, Zhang Y, et al. Origin and ablation of the adenosine triphosphate induced atrial fibrillation after circumferential pulmonary vein isolation: effects on procedural success rate. J Cardiovasc Electrophysiol 2014;25:36470. https://doi.org/10.1111/ice.12362: PMID: 24400741 17. Cheng H, Dai YY, Jiang RH, et al. Non-pulmonary vein foci induced before and after pulmonary vein isolation in patients undergoing ablation therapy for paroxysmal atrial fibrillation: incidence and clinical outcome. I Zhejiang Univ sei B 2014;15:915-22. https://doi.org/10.1631/jzus.B1400146; PMID: 25294381.

18. Kuroi A, Miyazaki S, Usui E, et al. Adenosine-provoked atrial fibrillation originating from non-pulmonary vein foci: the clinical significance and outcome after catheter ablation JACC Clin Electrophysiol 2015;1:127-35. https://doi.org/10.1016/j. jacep.2015.02.020; PMID: 29759355

19. Hayashi $K, A \cap Y$, Nagashima M, et al. Importance of nonpulmonary vein foci in catheter ablation for paroxysmal atrial fibrillation. Heart Rhythm 2015;12:1918-24. https://doi. org/10.1016/j.hrthm.2015.05.003; PMID: 25962801.

20. Lo LW, Lin YJ, Chang SL, et al. Predictors and characteristics of multiple (more than 2) catheter ablation procedures for atria fibrillation. I Cardiovasc Electrophysiol 2015:26:1048-56. https:/ doi.org/10.1111/jce.12748; PMID: 26178628

21. Hayashi K, Fukunaga M, Yamaji K, et al. Impact of catheter ablation for paroxysmal atrial fibrillation in patients with sick sinus syndrome - important role of non-pulmonary vein foci. Circ J 2016;80:887-94. https://doi.org/10.1253/circj.CJ-15-1384; PMID: 26936115.

22. Hasebe H, Yoshida K, lida M, et al. Right-to-left frequency gradient during atrial fibrillation initiated by right atrial ectopies and its augmentation by adenosine triphosphate: Implications of right atrial fibrillation. Heart Rhythm 2016;13:354-63. https://doi.org/10.1016/ hrthm.2015.09.030; PMID: 26432585 .

23. Zhao Y, Di Biase L, Trivedi C, et al. Importance of nonpulmonary vein triggers ablation to achieve long-term freedom from paroxysmal atrial fibrillation in patients with low ejection fraction. Heart Rhythm 2016;13:141-9. https://doi. org/10.1016/j.hrthm.2015.08.029; PMID: 26304713.

24. Santangeli P, Zado ES, Hutchinson MD, et al. Prevalence and distribution of focal triggers in persistent and long-standing persistent atrial fibrillation. Heart Rhythm 2016;13:374-82. https://doi.org/10.1016/j.hrthm.2015.10.023; PMID: 26477712

25. Hung Y, Lo LW, Lin YJ, et al. Characteristics and long-term catheter ablation outcome in long-standing persistent atrial fibrillation patients with non-pulmonary vein triggers Int I Cardiol 2017;241:205-11. https://doi.org/10.1016/1. ijcard. 2017.04.050; PMID: 28456483

26. Narui $R$, Matsuo $S$, Isogai $R$, et al. Impact of deep sedation on the electrophysiological behavior of pulmonary vein and non-PV firing during catheter ablation for atrial fibrillation. $J$ Interv Card Electrophysiol 2017;49:51-7. https://doi.org/10.1007/ S10840-017-0238-6; PMID: 28285382

27. Allamsetty $S$, Lo LW, Lin YJ, et al. Impact of aortic encroachment to left atrium on non-pulmonary vein triggers of atrial fibrillation. Int I Cardiol 2017;227:650-5. https://doi. org/10.1016/j.jijcard.2016.10.081; PMID: 27838125.

28. Takigawa M, Takahashi A, Kuwahara T, et al. Long-term outcome after catheter ablation of paroxysmal atrial fibrillation: Impact of different atrial fibrillation foci. Int J Cardio 2017;227:407-12. https://doi.org/10.1016/j.ijcard.2016.11.028 PMID: 27838128.

29. Takigawa M, Takahashi A, Kuwahara T, et al. Impact of nonpulmonary vein foci on the outcome of the second session of catheter ablation for paroxysmal atrial fibrillation. J Cardiovas Electrophysiol $2015 ; 26: 739-46$. https://doi.org/10.1111/ jce.12681; PMID: 25845757

30. Mohanty S, Mohanty P, Di Biase L, et al. Long-term followup of patients with paroxysmal atrial fibrillation and severe left atrial scarring: comparison between pulmonary vein antrum isolation only or pulmonary vein isolation combined with either scar homogenization or trigger ablation. Europace with either scar homogenization or trigger ablation. Europace 2017; 19:1790-7.

31. Cappato R, Negroni S, Pecora D, et al. Prospective assessment of late conduction recurrence across radiofrequency lesions producing electrical disconnection at the pulmonary vein ostium in patients with atrial fibrillation. Circulation 2003;108:1599-604. https://doi.org/10.1161/01. CIR.0000091081.19465.F1; PMID: 12963643

32. Higa S, Tai CT, Chen SA. Catheter ablation of atrial fibrillation originating from extrapulmonary vein areas: Taipei approach. Heart Rhythm. 2006;3:1386-90. https://doi.org/10.1016/j. hrthm.2006.09.006; PMID: 17074652

33. Higa S, Tai CT, Chen SA. Catheter ablation of paroxysmal atrial fibrillation originating from the non-pulmonary vein areas. In: Huang S, Wood M (eds). Catheter Ablation of Cardiac Arrhythmias. Philadelphia: Elsevier, 2006; 289-304.

34. Higa S, Lin YJ, Lo LW, et al. Catheter ablation of paroxysmal atrial fibrillation originating from the non-pulmonary vein areas. In: Huang S, Wood M (eds). Catheter Ablation of Cardiac areas. In. Huang S, Wood M (eds). Catheter Ablation of Cardiac

Arrhythmias. 2nd edn. Philadelphia: Elsevier, 2011, 265echocardiography-guided, anatomically based radiofrequency ablation of focal atrial fibrillation originating from pulmonary veins. J Am Coll Cardiol 2002;39:1964-72. https://do org/10.1016/S0735-1097(02)01893-4; PMID: 12084595.

36. Natale A, Pisano E, Beheiry S, et al. Ablation of right and left atrial premature beats following cardioversion in patients with chronic atrial fibrillation refractory to antiarrhythmic drugs. Am I Cardiol 2000;85:1372-5. https://doi.org/10.1016/ S0002-9149(00)00774-8; PMID: 10831959.

37. Jais $P$, Weerasooriya R, Shah DC, et al. Ablation therapy for atrial fibrillation (AF): Past, present and future. Cardiovasc Res 2002;54:337-46. https://doi.org/10.1016/S00086363(02)00263-8; PMID: 12062339.

38. Schmitt C, Ndrepepa G, Weber S, et al. Biatrial multisite mapping of atrial premature complexes triggering onse of atrial fibrillation. Am J Cardiol 2002;89:1381-7. https://doi. org/10.1016/S0002-9149(02)02350-0; PMID: 12062732.

39. Lee $\mathrm{SH}$, Tai CT, Hsieh MH, et al. Predictors of non-pulmonary vein ectopic beats initiating paroxysmal atrial fibrillation: implication for catheter ablation. J Am Coll Cardiol 2005;46:10549. https://doi.org/10.1016/j.jacc.2005.06.016; PMID: 16168291.

40. Keith A, Flack M. The form and nature of the primary divisions of the vertebrate heart. J Anat 1907;41:189. PMID: 17232727.

41. Chen YJ, Chen YC, Yeh HI, et al. Electrophysiology and arrhythmogenic activity of single cardiomyocytes from canine superior vena cava. Circulation 2002;105:2679-85. https://dol. org/10.1161/01.CIR.0000016822.96362.26; PMID: 12045176

42. Yeh HI, Lai YJ, Lee SH, et al. Heterogeneity of myocardial sleeve morphology and gap junctions in canine superior vena cava. Circulation 2001;104:3152-7. https://doi.org/10.1161/ hc5001.100836; PMID: 11748116.

43. Chang KC, Lin YC, Chen JY, et al. Electrophysiological characteristics and radiofrequency ablation of focal atrial tachycardia originating from the superior vena cava. Jpn Circ J 2001;65:1034-40. https://doi.org/10.1253/jcj.65.1034; PMID: 11767994

44. Ooie T, Tsuchiya T, Ashikaga K, et al. Electrical connection between the right atrium and the superior vena cava, and the extent of myocardial sleeve in a patient with atrial 
fibrillation originating from the superior vena cava. I Cardiovasc Electrophysiol 2002;13:482-5. https://doi.org/10.1046/j.15408167.2002.00482.x; PMID: 12030531.

45. Goya M, Ouyang F, Ernst S, et al. Electroanatomic mapping and catheter ablation of breakthroughs from the right atrium to the superior vena cava in patients with atrial fibrillation. Circulation 2002:106:1317-20. https://doi.org/10.1161/01. CIR.0000033115.92612.F4; PMID: 12221046.

46. Jayam VK, Vasamreddy C, Berger R, et al. Electrical disconnection of the superior vena cava from the right atrium. I Cardiovasc Electrophysiol 2004;15:614. https://doi. org/10.1046/j.1540-8167.2004.03414.X; PMID: 15149435.

47. Ino T, Miyamoto S, Ohno T, et al. Exit block of focal repetitive activity in the superior vena cava masquerading as a high right atrial tachycardia. I Cardiovasc Electrophysiol 2000;11:480-3. https://doi.org/10.1111/j.1540-8167.2000.tb00346.X; PMID: 10809504

48. Spach MS, Barr RC, Jewett PH. Spread of excitation from the atrium into thoracic veins in human beings and dogs. Am J Cardiol 1972;30:844-54. https://doi.org/10.1016/00029149(72)90009-4; PMID: 4634282

49. Zipes DP, Knope RF. Electrical properties of the thoracic veins. Am I Cardiol 1972;29:372-6. https://doi.org/10.1016/00029149(72)90533-4; PMID: 5060810

50. Hashizume H, Ushiki T, Abe K. A histological study of the cardiac muscle of the human superior and inferior venae cavae. Arch Histol Cytol 1995;58:457-64. https://doi.org/10.1679/ aohc.58.457; PMID: 8562136

51. Mary-Rabine L, Hordof AJ, Danilo P Jr, et al. Mechanisms for impulse initiation in isolated human atrial fibers. Circ Res 1980;47:267-77. https://doi.org/10.1161/01.RES.47.2.267; PMID: 7397958

52. Gelband H, Bush HL, Rosen MR, et al. Electrophysiologic properties of isolated preparations of human atrial myocardium. Circ Res 1972:30:293-300 https://do org/10.1161/01.RES.30.3.293; PMID: 5060431

53. Ten Eick RE, Singer DH. Electrophysiological properties of diseased human atrium. Circ Res 1979:44:545-57. https://doi. org/10.1161/01.RES. 44.4.545; PMID: 428050

54. Kalman JM, Olgin JE, Karch MR, et al. "Cristal tachycardias": Origin of right atrial tachycardias from the crista terminalis identified by intracardiac echocardiography. I Am Coll Cardia 1998;31:451-9. https://doi.org/10.1016/S0735-1097(97)004920; PMID: 9462592

55. Boineau JP, Canavan TE, Schuessler RB, et al. Demonstration of a widely distributed atrial pacemaker complex in the human heart. Circulation 1988;77:1221-37. https://doi. org/10.1161/01.CIR 77.6.1221: PMID: 3370764.

56. Hwang C, Chen PS: Clinical electrophysiology and cathete ablation of atrial fibrillation from the ligament of Marshall. In: Chen SA, Haissaguerre M, Zipes DP, (eds). Thoracic Vein Arrhythmias: Mechanisms and Treatment. Malden: Blackwell Futura, 2004;226-84. https://doi.org/10.1002/9780470751442.ch23

57. Scherlag BJ, Yeh BK, Robinson MJ. Inferior interatrial pathway in the dog. Circ Res 1972;31:18-35. https://doi.org/10.1161/01. RES.31.1.18; PMID: 5038734

58. Doshi RN, WU TJ, Yashima M, et al. Relation between ligament of Marshall and adrenergic atrial tachyarrhythmia. Circulation 1999: 100:876-83. https://doi.org/10.1161/01.CIR.100.8.876; PMID: 10458726

59. Erlanger J, Blackman JR. A study of relative rhythmicity and conductivity in various regions of the auricles of the mammalian heart. Am J Physiol 1907;19:125-74. https://doi. org/10.1152/ajplegacy.1907.19.1.125

60. Andrew LW, Paul FC. Triggered and automatic activity in the canine coronary sinus. Circ Res. 1977:41:435-45. PMID: 902353

61. Tsuji M, Kato K, Tanaka $\mathrm{H}$, et al. Pulmonary vein isolation for paroxysmal atrial fibrillation in a patient with stand-alone unroofed coronary sinus. HeartRhythm Case Rep 2017:3:248-50. https://doi.org/10 1016/j hrcr2017 02 002; PMID: 28736706.

62. Lee SH, Tai CT, Lin WS, et al. Predicting the arrhythmogenic foci of atrial fibrillation before atrial transseptal procedure: Implication for catheter ablation. I Cardiovasc Electrophysio 2000;11:750-7. https://doi.org/10.1111/j.1540-8167.2000. tb00046.x; PMID: 10921792

63. Frey $\mathrm{B}$, Kreiner $\mathrm{G}$, Gwechenberger $\mathrm{M}$, et al. Ablation of atrial tachycardia originating from the vicinity of the atrioventricula node: Significance of mapping both sides of the interatrial septum. J Am Coll Cardiol 2001;38:394-400. https://doi. septum. J Am coll Cardiol 2001;38:394-400. https.//dol.

64. Marrouche NF, Sippens-Groenewegen A, Yang Y, et al. Clinica and electrophysiologic characteristics of left septal atria tachycardia. J Am Coll Cardiol 2002;40:1133-9. https://doi. org/10.1016/S0735-1097(02)02071-5; PMID: 12354440.

65. Kuo JY, Tai CT, Tsao HM, et al. P wave polarities of an arrhythmogenic focus in patients with paroxysmal atrial fibrillation originating from superior vena cava or right superior pulmonary vein. J Cardiovasc Electrophysiol 2003;14: 350-7. https://doi.org/10.1046//.1540-8167.2003.02513.x PMID: 12741704

66. Lin YJ, Tai CT, Liu TY, et al. Electrophysiological mechanism and catheter ablation of complex atrial arrhythmias from crista terminalis: Insight from three-dimensional noncontact mapping. Pacing Clin Electrophysiol 2004;27:1232-9. https://do org/10.1111/j.1540-8159.2004.00614.x; PMID: 15461713.

67. Katritsis D, loannidis JP, Anagnostopoulos CE, et al. Identification and catheter ablation of extracardiac and intracardiac components of ligament of Marshall tissue for treatment ofparoxysmal atrial fibrillation. I Cardiovasc Electrophysiol 2001;12:750-8. https://doi.org/10.1046/j.15408167.2001.00750.x; PMID: 11469421

68. Polymeropoulos KP, Rodriguez LM, Timmermans C, et al. Images in cardiovascular medicine: Radiofrequency ablation of a focal atrial tachycardia originating from the Marshall ligament as a trigger for atrial fibrillation. circulation 2002;105:2112-3. https://doi.org/10.1161/01. CIR.000016168.49833CE: PMID: 11980693.

69. Calkins H, Brugada J, Packer DL, et al. HRS/EHRA/ECAS expert consensus statement on catheter and surgical ablation of atrial fibrillation: recommendations for personnel, policy, procedures and follow-up. Heart Rhythm 2007;4:816-61. https:// doi.org/10.1016/j.hrthm.2007.04.005; PMID: 17556213.

70. Lin YJ, Tai CT, Chang SL, et al. Efficacy of additional ablation of complex fractionated atrial electrograms for catheter ablation of nonparoxysmal atrial fibrillation. J Cardiovascular Electrophysiol 2009;20:607-15. https://doi.org/10.1111/j.15408167.2008.01393.x: PMID: 19642225

71. Lo LW, Lin YJ, Tsao HM, et al. Characteristics of complex fractionated electrograms in non-pulmonary vein ectopy initiating atrial fibrillation / atrial tachycardia. J Cardiovascular Electrophysiol 2009;20:1305-12. https://doi.org/10.1111/j.15408167.2009.01617.X.PMID: 19804543

72. Matsunaga-Lee Y, Takano Y. A novel mapping technique to detect non-pulmonary vein triggers: a case report of selfreference mapping technique. HeartRhythm Case Rep 2017;4:26 8. https://doi.org/10.1016/j.hrcr.2017.10.015; PMID: 29379722

73. Higa S, Lin YJ, Tai CT, et al. Noncontact mapping. In: Calkin H, Jais P, Steinberg I (eds). A Practical Approach to Catheter Ablation of Atrial Fibrillation. Philadelphia: Lippincott Williams \& Wilkins, 2008;118-33.

74. Weiss C, Willems S, Rostock T, et al. Electrical disconnection of an arrhythmogenic superior vena cava with discrete radiofrequency current lesions guided by noncontact mapping. Pacing Clin Electrophysiol 2003;26:1758-61. https://doi. org/10.1046/j. 1460-9592.2003.t01-1-00263 x; PMID: 12877711

75. Liu TY, Tai CT, Lee PC, et al. Novel concept of atrial tachyarrhythmias originating from the superior vena cava: Insight from noncontact mapping. J Cardiovasc Electrophysiol. 2003;14:533-9. https://doi.org/10.1046/j.15408167.2003.02473.x; PMID: 12776873

76. Huang BH, Wu MH, Tsao HM, et al. Morphology of the thoracic veins and left atrium in paroxysmal atria fibrillation initiated by superior caval vein ectopy. I Cardiovasc Electrophysiol. 2005;16:411-7. https://doi.org/10.1046/j.15408167.2005.40619.x: PMID: 15828887.

77. Chen SA, Tai CT. Catheter ablation of atrial fibrillation originating from the non-pulmonary vein foci. J Cardiovasc Electrophysiol 2005;16:229-32. https://doi.org/10.1046/j.15408167.2005.40665.x: PMID: 15720466.

78. Hsu LF, Jais $P$, Keane $D$, et al. Atrial fibrillation originating from persistent left superior vena cava. Circulation 2004;24;109:82832. https://doi.org/10.1161/01.CIR.0000116753.56467.BC PMID: 14757689.

79. Elayi CS, Fahmy TS, Wazni OM, et al. Left superior vena cava isolation in patients undergoing pulmonary vein antrum isolation: impact on atrial fibrillation recurrence. Heart Rhythm 2006;3:1019-23. https://doi.org/10.1016/j.hrthm.2006.05.024; PMID: 16945794.

80. Liu H, Lim KT, Murray C, et al. Electrogram-guided isolation of the left superior vena cava for treatment of atrial fibrillation. Europace 2007;9:775-80. https://doi.org/10.1093/europace/ eum118; PMID: 17557767

81. Tsutsui K, Ajiki K, Fujiu K, et al. Successful catheter ablation of atrial tachycardia and atrial fibrillation in persistent left superior vena cava. Int Heart J 2010;51:72-4. https://doi. org/10.1536/ihj.51.72; PMID: 20145356

82. Aras D, Cay S, Topaloglu S, et al. A rare localization for nonpulmonary vein trigger of atrial fibrillation: persistent left superior vena cava Int I cardiol 2015:187:235-6. https://do org/10.1016/j.ijcard.2015.03.309; PMID: 25838220

83. Abrich VA, Munro J, Srivathsan K. Atrial fibrillation ablatio with persistent left superior vena cava detected during intracardiac echocardiography. Hearthhythm Case Rep 2017: 3:455-8. https://doi.org/10.1016/j.hrcr.2017.06.004; PMID: 29062696

84. Huang S, Pan B, Zou H, et al. Cryoballoon ablation for paroxysmal atrial fibrillation in a case of persistent left superior vena cava. BMC Cardiovasc Disord 2018;18:51. https:// doi.org/10.1186/s12872-018-0789-1: PMID: 29534678.

85. Matsumoto $S$, Matsunaga-Lee $Y$, Masunaga $N$, et al. The usefulness of ventricular pacing during atrial fibrillation ablation in a persistent left superior vena cava: A case report. Indian Pacing Electrophysiol J 2018;18:155-8. https://doi. org/10.1016/j.ipej.2018.04.003; PMID: 29660447

86. Mansour M, Ruskin J, Keane D. Initiation of atrial fibrillation by ectopic beats originating from the ostium of the inferior vena cava. J Cardiovasc Electrophysiol 2002:13:1292-5. https://doi.org/10.1046/i.1540-8167.2002.01292.x PMID: 12521348.

87. Scavee $C$, Jais $P$, Weerasooriya $R$, et al. The inferior vena cava: An exceptional source of atrial fibrillation. I Cardiovasc Electrophysiol 2003;14:659-62. https://doi.org/10.1046/j.15408167.2003.03027.X; PMID: 12875429

88. Rotter M, Sanders P, Takahashi Y, et al. Images in cardiovascular medicine: Coronary sinus tachycardia driving atrial fibrillation. Circulation 2004;110:e59-60. https://doi. org/10.1161/01.CIR.0000138256.14084.C2; PMID: 15302808.

89. Sanders $\mathrm{P}$, Jais $\mathrm{P}$, Hocini $\mathrm{M}$, et al. Electrical disconnection of the coronary sinus by radiofrequency catheter ablation to isolate a trigger of atrial fibrillation. I Cardiovasc Electrophysiol 2004:15:364-8. https://doi.org/10.1046/j.15408167.2004.03300 x: PMID: 15030429

90. Yamada T, Murakami Y, Plumb VJ, et al. Focal atrial fibrillation originating from the coronary sinus musculature. Heart Rhythm 2006;3:1088-91. https://doi.org/10.1016/j.hrthm.2006.05.015; PMID: 16945808

91. Rostock T, Lutomsky B, Steven D, et al. The coronary sinus as a focal source of paroxysmal atrial fibrillation: more evidence for the 'fifth pulmonary vein'? Pacing Clin Electrophysiol 2007;30:1027-31. https://doi.org/10.1111/.15408159.2007.00805.x: PMID: 17669090

92. Tuan TC, Tai CT, Lin YK, et al. Use of fluoroscopic views for detecting Marshall's vein in patients with cardiac arrhythmias. I Interv Card Electrophysiol 2003;9:327-31. https:// doi. org/10.1023/A:1027435208576; PMID: 14618052.

93. Katritsis D, Giazitzoglou E, Korovesis S, et al. Epicardial foci of atrial arrhythmias apparently originating in the left pulmonary veins. I Cardiovasc Electrophysiol 2002;13:319-23. https://do . org/10.1046/j.1540-8167.2002.00319.x; PMID: 12033345.

94. Keida T, Fujita M, Okishige K, et al. Elimination of nonpulmonary vein ectopy by ethanol infusion in the vein of Marshall. Heart Rhythm 2013;10:1354-6. https://doi. org/10.1016/jhrthm.2013 07.019. PMID: 23867146.

95. Dave AS, Báez-Escudero JL, Sasaridis C, et al. Role of the vein of Marshall in atrial fibrillation recurrences after catheter ablation: therapeutic effect of ethanol infusion. J Cardiovasc Electrophysiol 2012;23:583-91. https://doi.org/10.1111/j.15408167.2011.02268.x; PMID: 22429895

96. Di Biase L, Schweikert RA, Saliba WI, et al. Left atrial appendage tip: an unusual site of successful ablation after endocardial and epicardial mapping and ablation. J Cardiovasc Electrophysiol 2010;21:203-6. https://doi.org/10.1111/j.15408167.2009.01561.X; PMID: 19656253

97. Pastor A, Núñez A, Magalhaes A, et al. The superior vena cava as a site of ectopic foci in atrial fibrillation. Rev ESD Cardiol 2007;60:68-71. https://doi.org/10.1016/S0300-8932(07)749874; PMID: 17288958

98. Higuchi K, Yamauchi Y, Hirao K, et al. Superior vena cava as initiator of atrial fibrillation: factors related to its arrhythmogenicity. Heart Rhythm 2010;7:1186-91. https://doi. org/10.1016/j.hrthm.2010.05.017; PMID: 20470902.

99. Chang HY, LO LW, Lin YJ, et al. Long-term outcome of catheter ablation in patients with atrial fibrillation originating from the superior vena cava. I Cardiovasc Electrophysiol 2012;23:955-61. https://doi.org/10.1111/.1540-8167.2012.02337.x; PMID: 22554079

100. Yang PS, Park JG, Pak HN. Catheter ablation for cold water swallowing-induced paroxysmal atrial fibrillation: a case report. Heart Rhythm 2014;11:2300-2. https://doi.org/10.1016/j. hrthm.2014.08.020; PMID: 25131663

101. Miyazaki S, Taniguchi H, Kusa S, et al. Factors predicting an arrhythmogenic superior vena cava in atrial fibrillation ablation: insight into the mechanism. Heart Rhythm 2014;11:1560-6. https://doi.org/10.1016/j.hrthm.2014.06.016; PMID: 24933296

102. Inada K, Matsuo S, Tokutake $K$, et al. Predictors of ectopic firing from the superior vena cava in patients with paroxysmal atrial fibrillation. I Interv Card Electrophysiol 2015;42:27-32. https://doi.org/10.1007/s10840-014-9954-3; PMID: 25398210

103. Esato M, Nishina N, Kida Y, et al. A case of paroxysmal atria fibrillation with a non-pulmonary vein trigger identified by intravenous adenosine triphosphate infusion. J Arrhythm 2015;31:318-22. https://doi.org/10.1016/j.joa.2015.03.004 PMID: 26550091

104. Sugimura S, Kurita T, Kaitani $K$, et al. Ectopies from the superior vena cava after pulmonary vein isolation in patients with atrial fibrillation. Heart Vessels 2016:31:1562-9. https://doi. org/10.1007/s00380-015-0767-9; PMID: 26518692.

105. Miranda-Arboleda AF, Munro J, Srivathsan K. Sinus node injury during adjunctive superior vena cava isolation in a patient with triggered atrial fibrillation. Indian Pacing Electrophysiol J 2016;16:96-8. https://doi.org/10.1016/j.ipej.2016.08.003; PMID: 27789000

106. Nagase $T$, Kato $R$, Asano $S$, et al. AF sustained in only a small area of SVC. Intern Med 2017:56:2239-40. https://do . org/10.2169/internalmedicine 8588-16: PMID. 28781320

107. Trindade MLZHD, Rodrigues ACT, Pisani CF, et al. Superio vena cava syndrome after radiofrequency catheter ablation for atrial fibrillation. Arq Bras Cardiol 2017;109:615-7. https://dol . org/10.5935/abc.20170168; PMID: 29364353

108. Enriquez A, Liang JJ, Santangeli P, et al. Focal atrial fibrillation from the superior vena cava. J Atr Fibrillation 2017;9:1593. https://doi.org/10.4022/jafib.1593; PMID: 29250296.

109. Yagishita A, Yamauchi Y, Miyamoto T, et al. Electrophysiological evidence of localized reentry as a trigger and driver of atrial fibrillation at the junction of the superior vena cava and right atrium. HeartRhythm Case Rep 2017:3:164-6. https://doi.org/10 1016/j hrcr 2016 10.005. PMID: 28491795.

110. Ebana Y, Nitta J, Takahashi Y, et al. Association of the clinical and genetic factors with superior vena cava arrhythmogenicity in atrial fibrillation. Circ / 2017;82:71-7. 
org/10.1253/circi.CJ-17-1352; PMID: 29877198

112. Kashimura S, Nishiyama T, Kimura T, et al. Vein of Marshal partially isolated with radiofrequency ablation from the endocardium. HeartRhythm Case Rep 2016;3:120-3. https://doi. org/10.1016/j.hrcr.2016.08.008; PMID: 28491784.

113. Inamura Y, Nitta J, Sato A, et al. Successful ablation for nonpulmonary multi-foci atrial fibrillation/tachycardia in a patien with coronary sinus ostial atresia by transseptal puncture and epicardial approach. Hearthhythm Case Rep 2017:3:272-6. https://doi.org/10.1016/j.hrcr.2017.03.003. PMID: 28736712

114. Chang SL, Tuan TC, Tai CT, et al. Comparison of outcome in catheter ablation of atrial fibrillation in patients with versus catheter ablation of atial et al Comparison of outco versus without the metabolic syndrome. Am J Cardio 2009;103:6772. https://doi.O
PMID: 19101232 .

115. Oakes RS, Badger TJ, Kholmovski EG, et al. Detection and quantification of left atrial structural remodeling with delayedenhancement magnetic resonance imaging in patients with atrial fibrillation. Circulation 2009;119:1758-67. https://doi. org/10.1161/CIRCULATIONAHA. 108.811877; PMID: 19307477.

116. Lee RJ, Kalman JM, Fitzpatrick AP, et al. Radiofrequency catheter modification of the sinus node for "inappropriate" sinus tachycardia. Circulation 1995;92:2919-28. https://doi. sinus tachycardia. Circulation 1995;92.2919-28.
org/10.1161/01.CIR.92.10.2919; PMID: 7586260.

117. Callans DJ, Ren JF, Schwartzman D, et al. Narrowing of the superior vena cava-right atrium junction during radiofrequency catheter ablation for inappropriate sinus tachycardia: Analysis with intracardiac echocardiography. I Am Coll Cardiol 1999;33:1667-70. https://doi.org/10.1016/S07351097(99)00047-9; PMID: 10334440

118. Man KC, Knight B, Tse HF, et al. Radiofrequency catheter ablation of inappropriate sinus tachycardia guided by activation mapping. J Am Coll Cardiol 2000;35:451-7. https://doi.
org/10.1016/S0735-1097(99)00546-X; PMID: 10676693.

119. Pappone C, Oral H, Santinelli V, et al. Atrio-esophageal fistula as a complication of percutaneous transcatheter ablation of atrial fibrillation. circulation 2004:109:2724-6. https://doi. org/10.1161/01.CIR.0000131866.44650.46; PMID: 15159294.

20. Shah D, Dumonceau JM, Burri H, et al. Acute pyloric spasm and gastric hypomotility: an extracardiac adverse effect of percutaneous radiofrequency ablation for atrial fibrillation. J Am Coll Cardiol 2005;46:327-30. https://doi.org/10.1016/J. jacc.2005.04.030; PMID: 16022963

121. Black-Maier E, Pokorney SD, Barnett AS, et al. Risk of atrioesophageal fistula formation with contact forcesensing catheters. Heart Rhythm 20;14:1328-33. https://doi. org/10.1016/j.hrthm.2017.04.024; PMID: 28416466.

122. John RM, Kapur S, Ellenbogen KA, et al. Atrioesophageal fistula formation with cryoballoon ablation is most commonly related to the left inferior pulmonary vein. Heart Rhythm 2017;14:184-9. https://doi.org/10.1016/j.hrthm.2016.10.018; PMID: 27769853.

123. Jhuo SJ, Lo LW, Chang SL, et al. Periesophageal vagal plexus injury is a favorable outcome predictor after catheter ablation of atrial fibrillation. Heart Rhythm 2016;13:1786-93. https://doi.org/10.1016/i hrthm.2016.05.020; PMID: 27236026.

124. Saha SA, Trohman RG. Periesophageal vagal nerve injury following catheter ablation of atrial fibrillation: a case report and review of the literature. HeartRhythm Case Rep 2015;1:252-6. https://doi.org/10.1016/j.hrcr.2015.04.006; PMID: 28491561.

125. Tsao HM, Wu MH, Higa S, et al. Anatomic relationship of the esophagus and left atrium: implication for catheter ablation of atrial fibrillation. Chest 2005;128:2581-7. https://doi. org/10.1378/chest.128.4.2581; PMID: 16236927.
126. Carroll BJ, Contreras-Valdes FM, Heist EK, et al. Multi-sensor esophageal temperature probe used during radiofrequency ablation for atrial fibrillation is associated with increased ablation for atrial fibrillation is associated with increased
intraluminal temperature detection and increased risk of esophageal injury compared to single-sensor probe. J Cardiovasc Electrophysiol 2013;24:958-64. https://doi. org/10.1111/jce.12180; PMID: 23746064.

127. Koranne K, Basu-Ray I, Parikh V, et al. Esophageal temperature monitoring during radiofrequency ablation of atrial fibrillation: a meta-analysis. J Atr Fibrillation 2016;9:1452. https://doi. org/10.4022/jafib. 1452; PMID: 29250252.

128. Tsuchiya T, Ashikaga K, Nakagawa S, et al. Atrial fibrillation ablation with esophageal cooling with a cooled waterirrigated intraesophageal balloon: a pilot study. J Cardiovasc Electrophysiol 2007;18:145-50. https://doi.org/10.1111/j.15408167.2006.00693.x; PMID: 17239114

129. Arruda MS, Armaganijan L, di Biase L, et al. Feasibility and safety of using an esophageal protective system to eliminate esophageal thermal injury: implications on atrial-esophageal fistula following AF ablation. J Cardiovasc Electrophysiol 2009;20:1272-8. https://doi.org/10.1111/i.15408167.2009.01536.X; PMID: 19572955.

130. Parikh V, Swarup V, Hantla J, et al. Feasibility, safety, and efficacy of a novel preshaped nitinol esophageal deviator to successfully deflect the esophagus and ablate left atrium to successfully deflect the esophagus and ablate left atrium
without esophageal temperature rise during atrial fibrillation without esophageal temperature rise during atrial fibrillation
ablation: The DEFLECT GUT study. Heart Rhythm 2018;15:1321-7. https://doi.org/10.1016/j.hrthm.2018.04.017; PMID: 29678784.

131. Kuwahara T, Takahashi A, Takahashi Y, et al. Clinical characteristics of massive air embolism complicating left atrial ablation of atrial fibrillation: lessons from five cases Europace 2012:14:204-8. https://doi.org/10.1093/europace/ eur314; PMID: 21937478. 